\title{
Е.В. Пинюгина
}

\section{РОССИЯ И ФОРМИРОВАНИЕ \\ ЕВРАЗИЙСКИХ МЕЖГОСУААРСТВЕННЫХ TРАНСПОРТНЫХ ПРОЕКТОВ*}

Аннотация. В статье рассматриваются политические причины формирования проектов межгосударственных транспортных коридоров азиатскими государствами. Анализируется влияние международной обстановки на альянсы в транспортной сфере между странами, риски и возможности участия в них для России.

Ключевые слова: транспортные коридоры, транспортные проекты, Индия, Китай, геополитическая конкуренция, арктический транспортный коридор.

Пинюгина Елена Викторовна - кандидат политических наук,

научный сотрудник Отдела политической науки

Института научной информации по общественным наукам РАН

(ИНИОН РАН), Москва. E-mail: pinjugina@mail.ru

E.V. Piniugina. Russia's Role in the Formation of the Eurasian Interstate Transport Projects

Abstract. The article studies political reasons of the international transport corridors projects' formation by Asian states. The author analyzes the influence of international factors on transport alliances, possible risks and opportunities for Russia's participation in it as well as tendencies of Russia's development in inner and international transport communications in Arctic.

Keywords: transport corridors, transport projects, India, China, the geopolitical competition in the Arctic transport corridor.

\footnotetext{
* Статья подготовлена в рамках гранта № 16-27-21001 РГНФ «Формирование общего экономического пространства в Евразии: Исследование вопросов сопряжения строительства Экономического пояса Шёлкового пути и Евразийского экономического союза» (Международный конкурс РГНФ - Китайская академия общественных наук (KAOH) 2016 2.)
} 
Piniugina Elena Viktorovna - candidate of Political sciences,

Researcher of the Department of political science,

the Institute of Scientific Information on Social Sciences

of the Russian Academy of Sciences (INION RAN), Moscow.

E-mail: pinjugina@mail.ru

В результате наращивания азиатскими странами своих индустриальных мощностей и усиления их человеческого потенциала азиатская часть евразийского континента превратилась в одну из несущих конструкций мировой экономики. Возвышение азиатских государств заставляет их переосмысливать те аспекты экономического развития и международных отношений, где пересекаются национальные интересы и геополитические амбиции. Такой областью пересечения стала сфера международных транспортных коммуникаций.

Особенно это касается двух гигантов Евразии - Китая и Индии, конкурирующих за доминирование в Юго-Восточной Азии, наращивающих активность в Африке, осваивающих рынки постсоветских среднеазиатских стран и новые способы транзита своих экспортных товаров в Европу. Столкновение интересов и амбиций находит выражение в стратегиях развития межгосударственных транспортных коридоров. Более того, транспортные геополитические стратегии способствуют формированию новых межгосударственных альянсов, укреплению связей или углублению имеющихся расхождений. Перед Россией этот «век Азии», особенно учитывая ухудшение отношений с Западом, напоминающий период холодной войны, возможно, открывает определенные перспективы. России поступили предложения от КНР участвовать в инициативе «Один пояс, один путь», также известной как «Новый шёлковый путь» (НШП), от Индии - в международном транспортном коридоре «Север-Юг» (МТКСЮ).

Эти два самых масштабных транспортных проекта XXI в., в которых решила участвовать Россия, охватывают Евразийский континент соответственно расположению стран-инициаторов: Индия лоббирует МТКСЮ, а китайский Новый шёлковый путь (официальное название «Один пояс, один путь», далее ОПОП) преимущественно сконцентрирован на маршрутах, соединяющих Восток и Запад. Обе страны имеют не только сопоставимый экономический потенциал (несмотря на существенное пока превосходство Китая) и статус ядерных держав, но и сравнимые растущие потребности в источниках энергии, а также в рынках сбыта своего экспорта. Помимо естественного соперничества отношения этих стран осложняет ряд «замороженных» территориальных споров (Транс-Каракорумское шоссе, район Аксайчин, штат Аруначал - Прадеш), а также давнее и тесное партнерство КНР с Пакистаном, суверенитет которого над частью Кашмира Индия так и не признала. Существуют и другие экономические и политические разногласия. 158 
Обе страны с начала XXI в. стремятся к достижению паритета возможностей в сфере международных транспортных коммуникаций, подобно тому, как в XX в. страны-соперники стремились к паритету в стратегических вооружениях или в освоении космоса. Индия задолго до появления китайского НШП лоббировала проект МТКСЮ протяженностью более 5000 км, который свяжет Южную и Центральную Азию, Кавказ, Россию и Европу, сократив путь из Азии в Европу в 2 раза по сравнению с традиционной морской транспортировкой через Суэцкий канал. Тремя странами - учредителями проекта в 2000 г. - стали Индия, Россия и Иран, подписавшие трехстороннее соглашение. Ожидалось, что сухопутный транзит по территории России и Ирана составит большую часть комбинированного (включающего морской, железнодорожный и автодорожный компоненты) маршрута, в результате чего на $40 \%$ сократится время доставки грузов из Индии в Европу и на $30 \%-$ стоимость. Проект забуксовал и перешел в «замороженное» состояние из-за наложенных на Иран санкций. Он вновь стал востребованным на фоне «разворота» России на Восток, снятия с Ирана санкций и обострения конкуренции Индии и Китая в связи с активизаций КНР в Центральной (ЦА) и ЮгоВосточной (ЮВА) Азии.

Спустя 15 лет три страны-учредителя согласовали обновленный маршрут МТКСЮ: от индийского порта Мумбай через Аравийское море в иранский порт Бандар-Аббас в Персидском заливе, оттуда железной дорогой в каспийские порты на севере Ирана - Ноушехр или Энзели. С иранского побережья Каспийского моря транспортировку можно осуществлять как морем (до российских портов Оля, Махачкала или Астрахань), так и по суше, вдоль побережья Каспийского моря в Астрахань, а от нее железной дорогой до порта Санкт-Петербург, с выходом на Северную Европу. При этом, как и у китайского Экономического пояса Шёлкового пути (ЭПШП), возможны вариации маршрута - с Запада и с Востока от Каспийского моря: либо через Кавказ, где транзитной страной становится Азербайджан, либо через центральноазиатские страны - Туркменистан и Казахстан. Западный маршрут удобнее для торговли с Поволжьем и южными регионами РФ, а восточный маршрут - для грузополучателей и отправителей Урала и Сибири. Однако для успешного развития коридора необходима не только заинтересованность в транзите на противоположных концах Евразии, но и интенсификация торговли стран по ходу маршрута между собой, иначе невозможно обеспечить загрузку судов, грузовых поездов и фур, чтобы удешевить оплату доставки, а без этого коридор не станет привлекательнее традиционного маршрута через Суэцкий канал. Товарооборот России с Ираном и Индией недостаточно разнообразен, но есть перспективы оживления торговли за счет экспорта российских автомобилей, полудрагоценных камней и зерна, импорта иранских специй, овощей и фруктов, индийского текстиля и т.п. 


\section{РОССИЯ И МИР В ХХІ ВЕКЕ}

Используя проект МТКСЮ, Индия выбрала схожую с китайской стратегию. Если КНР под эгидой «Пояса и пути» объявила приоритетным Китайско-Пакистанский экономический коридор (КПЭК), то Индия разработала дополнительный коридор «Юг - Запад» (КЮЗ). КЮЗ связывает индийские порты с иранским портом Чабахар в Ормузском проливе, далее маршрут следует по территории Ирана и Афганистана. Афганистан имеет выход на туркменскую железнодорожную сеть и может быть как конечным пунктом для экспорта из Индии и стран Персидского залива, так и транзитным для проникновения Индии на рынки постсоветских стран ЦА. В основе проекта трехстороннее соглашение Индии, Ирана и Афганистана, но расходы на себя берет Индия. Инвестором порта становится индийская государственная компания, на которой целиком лежит ответственность за доведение грузооборота порта до расчетных 12 млн т в год; индийский госбанк открыл кредитную линию в 500 млн долл. для строительства железнодорожной ветки от порта Чабахар до Захедана на ирано-афганской границе. Близость порта Чабахар, на который Индия тратит столько ресурсов, к пакистанскому порту Гвадар, отданному в управление китайской компании, заставляет усомниться не только в экономической целесообразности проекта развития Чабахар, но и в его экономической окупаемости. Скорее, для Индии расширение возможностей для маневра в этих водах и усиление ее влияния в ЦА, которая считалась зоной конкуренции России, КНР и США, становится вопросом стратегического паритета и престижа.

Чтобы оценить экономическую и политическую составляющую в индийском проекте «Юг - Запад», можно сравнить рост экспорта КНР и Индии в страны ЦА за первые 15 лет нашего столетия. В 2001 г. КНР экспортировала в ЦА товары на сумму около 0,5 млрд долл., а в 2015 г. - на 18 млрд долл., тогда как соответствующие показатели Индии - 100 млн долл. в 2001 г. и 950 млн долл. в 2015 г.: экспорт КНР вырос в 36 раз, а Индии - в 9,5, хотя расстояние от Алматы до Дели в 2,5 раза меньше, чем до ближайших к ЦА западных промышленных провинций КНР. За эти 15 лет сопоставимыми с китайскими темпами рос только экспорт Индии в Афганистан (в 25 раз) [6].

Вероятно, полагая афганское направление в любом случае экономически выгодным, Индия уже построила автомобильную 200-километровую дорогу, ответвление от основной трассы Кандагар - Герат. В мае 2017 г. по коридору «Юг - Запад» запущен пробный груз, а для привлечения клиентов индийской управляющей компанией в порту практически введено субсидирование тарифов на хранение (75\%-ные скидки для иностранных и $85 \%$-ные - для иранских грузоотправителей). В ближайшее время завершатся работы по углублению порта Чабахар, которые позволят принимать океанские суда водоизмещением 100 тыс. т. Пропускная способность порта должна соста- 
вить до 8,5 млн, если, конечно, не принимать в расчет конкуренцию «индийского» Чабахара с «китайским» портом Гвадар.

Риски, на которые пошла Индия, ввязываясь в реализацию проекта «Юг Запад», подтверждает тот факт, что в период строительства автотрассы по территории Афганистана были убиты более 100 индийских рабочих. Уязвима и строящаяся железная дорога от Чабахара до Деларама, перевалочной станции на территории Афганистана, так как на афганском отрезке она пройдет в зоне, контролируемой скорее Талибаном, чем правительством; сохранность и доставка грузов (а значит, и репутация коридора) в этой связи ненадежна. Принимать во внимание Индии придется и политические риски: Иран установил неофициальные связи с движением Талибан, а из-за финансовой поддержки им нескольких группировок осложняются его отношения с официальным Кабулом (там создан комитет по расследованию связей Ирана и Талибана). Это создает для США возможность обвинить Иран в поддержке террористов и снова наложить санкции на проекты с участием Ирана.

Нельзя сказать, что, в отличие от Индии, Китай не рискует. Проводя к Гвадару автомобильные пути через неспокойные провинции Пакистана, строители подвергаются угрозам и нападениям представителей разных племен, работа проходит под охраной китайских военных или наемников из частных военных компаний, а местные националисты вообще против модернизации порта: доходы от него получит не местная власть, а федеральное правительство Пакистана. Но экономические риски Китая оправданы стремлением создать независимый от контроля американцев и их союзников альтернативный Малаккскому проливу коридор для снабжения страны энергоресурсами и диверсифицировать каналы вывоза китайского экспорта. Индия же и без Чабахара может для развития МТКСЮ пользоваться иранским портом Бендер-Аббас, который связан железной дорогой с Туркменией, а через нее с Казахстаном и Россией. Таким образом, вкладываясь в афганский транзит дополнительно к МТКСЮ, Индия доказывает приверженность идеологии, выраженной в принятой в 2012 г. ее внешнеполитической доктрине «Связать Центральную Азию» («Connect Central Asia»). Индию в ее намерении развивать порт Чабахар поддерживает Япония, заинтересованная в сдерживании Китая и готовая софинансировать индийский проект модернизации иранского порта. При этом, играя с Китаем на его поле, Индия получает неоднозначные сигналы от Вашингтона: то о желательности создания для Афганистана с помощью коридора «Юг - Запад» выхода к морю не через Пакистан (следовательно, задействуя Иран), то о недопустимости тесного сближения с Ираном.

Обращает на себя внимание то, что Иран играет ключевую роль как в экономически привлекательном для России и Индии проекте МТКСЮ, так и в стратегически важном для Индии проекте «Юг - Запад». Можно сопоставить значение Ирана в планах Индии с ролью Казахстана в трансъевра- 
зийских коридорах Китая в рамках НШП (несколько комбинаций маршрутов из КНР в Европу проходят большую часть пути по казахской территории ${ }^{1}$ ). Конкурентное преимущество МТКСЮ для Индии и России заключается в том, что запуск проекта не связан с огромными вложениями в инфраструктуру - за исключением нескольких участков она уже построена и функционирует, оставшиеся участки будут достроены в ближайшее время. Тогда как именно от Ирана требуется большее участие.

Иран, чье геополитическое значение в контексте проектов ЭПШП и МТКСЮ возросло, особенно с учетом снятия с него западных санкций, не имеет столь масштабных амбиций, как Индия и Китай, но готов конкурировать с ними, с Россией и Турцией за влияние в ЦА и на Ближнем Востоке. Заявленные проекты с участием Ирана могут видоизменяться в процессе международных консультаций и обсуждения отдельных аспектов их реализации. Соответственно, России необходимо следить за переговорами Ирана с его региональными партнерами без ее участия относительно возможных модификаций МТКСЮ, которые могут негативно повлиять на загруженность российских портов, железных дорог и всего российского транзита.

Свою вариацию маршрутов в рамках ЭПШП и МТКСЮ продвигает Азербайджан. По его территории в 2017 г. запустят новую, построенную за десять лет железнодорожную ветку Баку - Тбилиси - Карс, связывающую Азербайджан через Грузию с Турцией наиболее коротким маршрутом по суше (из Турции поезда через тоннель Мармарай под Босфором доставят грузы в Европу). Кавказско-турецкая ветка избавляет от необходимости переваливать грузы, следующие из Азии, через два моря: Каспийское и Черное; морским участком останется только Каспийская переправа. Но и этот «неудобный» этап транспортировки Азербайджан планирует превратить в комфортную интегральную часть любых коридоров, следующих через Евразию. Государство инвестирует в новый каспийский хаб - свободный порт Алят (в 20 км от Баку), проект которого разработан по образцу портов Роттердама и Гамбурга. Подписано соглашение с Казахстаном о создании совместного предприятия для развития грузовых и пассажирских перевозок между портами Курык (Актау) и Алят (Баку). Такой транскаспийский срез для транзита, идущего по МТКСЮ и по маршрутам НШП, означает как минимум сокращение пути, а как максимум - возможность обойтись без России. Для трех государств бывшего СССР - Казахстана, Азербайджана и Грузии - это успешная реализация подписанного в 2016 г. соглашения о создании Ассоциации «Транскаспийского международного транспортного маршрута» (ТМТМ). Для России такое усиление азербайджанского логистического потенциала несет

1. Подробнее см. об этом: [3]. 
риск потенциального снижения загрузки Транссиба в рамках НШП и упущенной выгоды для российских портов Астрахань, Оля, Махачкала в рамках МТКСЮ.

Дальнейшее развитие такой комбинации маршрутов китайского ЭПШП и индийского МТКСЮ через ЦА и Кавказ может негативно сказаться на отношениях РФ с партнерами по ЕАЭС и СНГ. Вовлеченность Казахстана в коридор в обход России снизит его заинтересованность в России, обеспеченную в том числе и совместной работой в рамках ЕАЭС и Таможенного союза по интеграции китайско-казахско-российского маршрута, завязанного на Транссиб. Азербайджан, вступивший на кавказском участке коридоров в тандем с Грузией, тем самым снижает конкурентоспособность западного маршрута МТКСЮ, несмотря на подтвержденную заинтересованность участия в нем и подписание с Россией в начале 2017 г. соответствующих договоренностей: Азербайджан, Иран и Россия решили снизить тарифы за грузоперевозки до 50\%, чтобы Индия и другие страны Южной Азии и Персидского Залива начали активнее использовать МТКСЮ. Такие же льготы были согласованы и для северных поставщиков, которые должны обеспечить обратную загрузку коридора, а значит, его рентабельность.

Одновременно с инициативами Азербайджана партнер России по ЕАЭС Армения лоббирует включение своей территории в западную ветку МТКСЮ, но это очень дорогостоящий и трудоемкий проект как для маленького государства, так и для потенциальных инвесторов ввиду необходимости пробить множество горных тоннелей. Вложить средства в армянский отрезок пути ориентировочной стоимостью 3,2 млрд долл. Иран и Россия пока не готовы, а у Армении до сих пор не появилось заинтересованных крупных инвесторов, кроме Китая, банки которого предположительно готовы кредитовать до $60 \%$ расходов по строительству этого железнодорожного коридора. В 2016 г. появилась информация, что вместо Китая новым интересантом включения Армении в западный коридор «Север - Юг» становится Индия, а в обновленный маршрут входит и часть территории Грузии. Такой вариант, как и маршрут Баку - Тбилиси - Карс и морские перевозки Актау - Баку снижает заинтересованность азиатских участников МТКСЮ в российском транзите. Снятие международных санкций с Ирана позволяет ему сделать ставку на европейское направление, а усиление санкционных ограничений в отношении России осложняет реализацию проектов с ее участием. Поэтому Иран теоретически благодаря армяно-грузинской ветке может переориентировать свой грузопоток с России на Кавказ и Европу.

Россия не менее активно, чем Иран, использует возможности, открывшиеся благодаря геополитическим устремлениям азиатских стран выстроить под себя евразийские транспортные коммуникации, и не только в транспортной сфере. 
Российская «Роснефть» стала владельцем 49\% индийской крупнейшей нефтяной корпорации Essar Oil Limited (EOL), приобретя тем самым долю в инфраструктуре индийского транспортного и топливно-энергетического комплекса, включая морской порт, один из крупнейших в мире нефтеперерабатывающих заводов Вадинар, электростанцию и несколько тысяч АЗС. Следующим этапом стало подписание на МЭФ в Санкт-Петербурге в июне 2017 г. соглашений о участии России в строительстве двух реакторов для АЭС в штате Кашим - Напур. Вероятно, такие вложения в индийский ТЭК могут, при достаточных дипломатических усилиях России, послужить аргументом для интенсификации грузопотока именно по МТКСЮ через территорию России, а не через возможные ответвления.

Россия не ограничивается пассивной ролью наблюдателя за формированием нового облика «Большой Евразии» [2]. Как и другие страны, оказавшиеся «на пути» масштабной инициативы КНР, Россия выстраивает совместную работу с Китаем, исходя из своих приоритетов. В первую очередь это социально-экономическое развитие своих территорий, северных и дальневосточных регионов, и улучшение коммуникаций как между российскими регионами, так и между промышленными районами и инфраструктурными узлами. Для достижения поставленных целей Россия планирует комплексное использование уникального сочетания преимуществ российской Арктики: арктические воды являются естественным морским МТК из Азии в Европу; арктический шельф и северные территории страны содержат разведанные и доказанные запасы углеводородов. Это вызывает интерес инвесторов к транспортной сфере Севера Евразии; оставшееся от Советского Союза инфраструктурное наследие может быть дополнено при участии иностранных инвестиций. Вторым приоритетом российского подхода в контексте восхождения Азии является сопряжение российского и китайского геополитических проектов - ЕАЭС и ЭПШП, чтобы в выигрыше остались все участники.

Арктическая политика России базируется на необходимости больших инвестиций в безопасность. Действия России в последние годы направлены на поддержание своего статуса доминирующей в Арктике военной державы, защиту крупных объемов природных ресурсов российского шельфа арктического бассейна и коммерциализацию Северного морского пути (СМП). Военные расходы в арктической части России приравниваются к инвестициям в безопасность, а военные объекты становятся частью инфраструктуры северных морских и сухопутных коммуникаций, проходящих по пустынным землям и водам. Для потенциальных инвесторов это повышает привлекательность их присутствия в Арктике. Как и Китай, который главной задачей ОПОП считает развитие удаленных территорий, Россия планирует стимулировать экономический рост ее северных территорий за счет международного 
интереса к транспортным и энергетическим аспектам своей арктической программы.

Китай представляется наиболее подходящим партнером, так как он не является арктическим государством, оспаривающим российский суверенитет или размещающим у себя американские вооружения. Китай заинтересован и в углеводородах, и в транспортировке Северным морским путем грузов, чтобы перенаправить с южного маршрута часть своего трафика Шанхай Гамбург. Конкурентные преимущества СМП для КНР - сокращение на десять суток времени доставки по сравнению с привычным маршрутом через Суэцкий канал, экономия топлива и, главное, снижение зависимости страны от морских транспортных коммуникаций юга Евразии. Последние уязвимы, находясь под контролем глобального гегемона - США, что усиливается желанием единственного соперника КНР в Азии (и американского союзника) Индии - отстоять право считать Индийский океан «своими территориальными водами». Инструментами для отстаивания Индией своей позиции являются ее военно-морские базы на Андаманских и Никобарских островах. Угрозу стабильности перевозок дополняют регулярные совместные учения военноморских сил стран АТР, которые организуются США для устрашения Китая. Такие учения в составе флотов США, Индии, Японии, Австралии происходили и в 2017 г. на фоне обострения индийско-китайского противостояния на плато Доклам. Существенные риски для китайских перевозок по южным морям создают и морские пираты, тогда как СМП лишен этих недостатков и угроз.

Экономически, по состоянию на сегодняшний день, Севморпуть оправдывает расходы, очень востребован российскими компаниями [4] и доказывает своим траффиком удобство и безопасность грузоперевозок: 12 млн т в год, показатель, вдвое превышающий уровень наивысшей загрузки этого коридора периода СССР (1987) [5]. Помимо России и Китая, СМП может быть выгоден и Японии: северный маршрут Иокагама - Гамбург короче и дешевле южного.

Партнерство с КНР по арктической программе уже началось и в топливно-энергетической, и в транспортной сферах: в условиях закрытия западных кредитов и довольно высокой стоимости кредитов российских банков [1] кредитование Экспортно-импортным банком Китая и Банком развития Китая на сумму более 10 млрд долл. позволило российской компании «Новатэк» на лучших для себя условиях реализовывать проект строительства на Ямале завода по сжижению природного газа («Ямал СПГ»), 20\% которого принадлежит китайской компании CNPC, а еще 9,9\% - фонду Шёлкового пути (Silk Road Fund). Воротами на Ямал и одновременно гаванью по маршруту Севморпути стал арктический российский хаб Сабетта, построенный на северовосточном побережье Ямала с нуля и заработавший в 2017 г. 


\section{РОССИЯ И МИР В ХХІ ВЕКЕ}

Заинтересованность клиентов в использовании СМП позитивно сказывается на отечественной судостроительной промышленности: на Балтийском заводе разворачивается строительство крупных атомных ледоколов, необходимых для проводки к порту Сабетта танкеров-гигантов. Для других нужд Севморпути российским судостроителям заказаны дизель-электрические ледоколы средних размеров. Непосредственно для транспортировки по Севморпути с Ямала российского СПГ создан новый класс судов - арктических газовых танкеров, первый из которых уже совершил весной 2017 г. рейс в порт Сабетта, однако заказы на арктические газовозы получает и Южная Корея. Сабетта - первый, но не единственный новый арктический порт. В рамках федеральной целевой программы «Развитие транспортной системы РФ до 2020 года» запланировано строительство еще нескольких новых портов в ЯНАО, помимо Сабетты, а также модернизация северных портов Чукотки, Якутии и Красноярского края, что в совокупности с военными расходами обеспечит геополитическое доминирование России в арктических коммуникациях.

Вкладывая средства в прибрежную портовую инфраструктуру, Россия рассчитывает на превращение Арктики в логистически привлекательный регион, планируя дополнить Севморпуть строительством двух сухопутных коридоров: Северного широтного хода (СШХ) и «Белкомура».

СШХ свяжет порт Сабетта с железнодорожной сетью, по которой в него пойдут грузы с Урала и Сибири, для этих грузов именно СМП станет оптимальным способом достичь рынков Дальнего Востока и Азиатско-Тихоокеанского региона в целом. По прогнозам Минтранса, с учетом потенциала СШХ через Сабетту будет проходить 70 млн т грузов в год, что сопоставимо с грузооборотом порта Санкт-Петербург. СШХ позволит не только открыть новые ворота на Восток, но и ускорить транспортировку грузов с Урала и доставку сырья с месторождений Западной Сибири в порты Северо-Запада России и далее - в Европу. За период 2012-2017 гг. в рамках развития СШХ уже возводится инфраструктура - автодорога Надым - Салехард, мост через реку Надым. Железнодорожное сообщение запустят по маршруту Обская - Салехард - Надым - Пангоды - Новый Уренгой - Коротчаево. В 2017 г. ПАО «Газпром» и ОАО «РЖД» подписали соглашение о совместной реализации СШХ и вводе в эксплуатацию 707 км новых путей до 2022 г. Государство выступит концедентом инвестиционного проекта, а дочерние структуры двух монополий - концессионерами. Часть маршрута от Надыма до Пангоды профинансирует и введет в эксплуатацию «Газпром», заинтересованный в начале освоения разведанных запасов газоконденсата в центральных районах ЯНАО, а также на полуострове Гыдан. Дочернее общество ОАО «РЖД» профинансирует и построит часть маршрута Обская - Салехард - Надым, включая железнодорожные части мостов через реки Обь и Надым, а также выполнит 166 
реконструкцию тех частей Северной и Свердловской железной дороги, которые интегрируются в проект СШХ.

Белкомур (сокращение от «Белое море - Коми - Урал») - это еще один арктический транспортный проект (и одновременно одноименное акционерное общество, учредителями которого являются Архангельская область, Республика Коми и Пермский край). Белкомур свяжет сетью железных дорог промышленно развитые регионы Сибири и Урала с портами Севера и СевероЗапада (Сабетта, Архангельск, Мурманск, Беломорск), что позволит перевозить по сети до 35 млн т грузов в год и сократить путь к российским портам на 800 км. Общая протяженность Белкомура составит 1155 км, а собственно нового строительства - 715 км. Российские крупные предприятия-поставщики, такие как «Еврохим» и «Уралкалий», существенно сэкономят на транспортировке: до 100 млн долл. в год, часть этих средств может быть инвестирована в новые технологии добычи и модернизацию производств. Среди интересантов Белкомура не только предприятия Пермского края, Кузбасса, Поволжья. Китай, основной импортер калийных удобрений, поставляемых из Березниковско-Соликамского промышленного узла, наравне с поставщиками заинтересован в сокращении сроков и снижении тарифов за счет скорейшего развития «Белкомура». В 2017 г. проект Белкомур получил полную поддержку Министерства коммерции и Министерства транспорта КНР, а китайский Эксимбанк выразил готовность открыть под него кредитную линию. Китайская компания Poly Group в рамках проекта Белкомур выступает инвестором строительства глубоководного порта в Архангельске и рассматривает другие объекты для финансового участия. На федеральном уровне полагают, что помимо трех ключевых, давших название проекту, регионов, от него выиграют еще несколько сопредельных. Инфраструктурные дивиденды рассчитывает получить и ОАО «РЖД», планируя с помощью частных инвесторов проекта осуществить так называемую «расшивку» некоторых железнодорожных узлов (Кировского и Соликамско-Березниковского) и модернизацию старых путей.

Второе «окно возможностей» для России, связанное с восхождением Азии, открылось после решения глав КНР и РФ в 2015 г. о сопряжении ЕАЭС и Экономического пояса Шёлкового пути (ЭПШП), сухопутной составляющей проекта ОПОП. Сопряжение происходит в двух измерениях: настоящего и будущего. В настоящем оно выражается в росте грузоперевозок из Китая в Европу по Транссибу, несмотря на объективные недостатки российского таможенно-логистического сервиса и инфраструктуры. В период 2013-2017 гг. из Китая в Европу отправлено более 4 тыс. контейнерных составов, включая восемь маршрутов, регулярно следующих через российский Забайкальск и далее по Транссибу. В совокупности маршруты из 28 городов Китая через Россию отправляются в 29 городов 11 стран Европы. Почти каждая китайская 
провинция планирует запускать в течение года от одного до семи новых маршрутов поездов в Европу, поскольку власти провинций полностью компенсируют экспортерам расходы на транспортировку.

Используя эту благоприятную конъюнктуру, Россия с партнерами по Евразийскому союзу работает над усилением транзитных преимуществ: унификацией тарифов и таможенных правил стран-участниц. Китай взвешивает свой инвестиционный потенциал относительно масштабных инфраструктурных объектов в условиях ограниченного доступа российской стороны к западным кредитам. Приоритеты сторон уточняются, выявляются наиболее реалистичные и приоритетные проекты. Для России важнейший вопрос развитие Дальнего Востока и интеграция территорий Дальнего Востока, Урала и Сибири в торгово-хозяйственные связи с европейской частью России. Китаю важно обеспечить выход к морю и к рынкам ЦА материковых провинций страны. Прогрессу в решении приоритетных для двух стран задач способствуют развитие инфраструктуры транспортного сообщения и содействие бизнесу в оптимизации грузоперевозок. Логистические схемы оптимизируются, упрощается регулирование.

Так, с декабря 2016 г. в рамках так называемого Северного коридора ЭПШП (КНР - Монголия - РФ) логистические компании трех стран сформировали и запустили маршрут Mongolian Schuttle, стартующий в г. Тянцзинь (КНР), и транзитом через монгольскую территорию прибывающий через 14 суток в Москву. На основе договоренностей РЖД и китайских партнеров от 2015 г. отработана новая схема взаимодействия портов и железных дорог, сократившая время доставки из Шанхая в Москву с 29 до 20 дней. Из Шанхая грузы морем доставляются в порт Инкоу провинции Ляонин, далее поездом до российской пограничной станции Забайкальск, оттуда за шесть дней вместо прежних 14 - в Москву. Преимущества использования новой схемы управления коридором «порт - железная дорога» позволили российским компаниям запустить с августа 2017 г. внутрироссийский регулярный грузовой поезд порт Владивосток - Екатеринбург, отрабатываются и маршруты Владивосток - Новосибирск и Владивосток - Ульяновск. Обратный грузопоток задействует не только порт Владивосток, но и российский порт Восточный.

Есть примеры и точечных инфраструктурных проектов, введение которых в эксплуатацию позволит получить общую выгоду. В июле 2017 г. президенты Путин и Си Цзиньпин подписали договоренности о развитии двух маршрутов - Приморье-1 и Приморье-2, связывающих материковые северо-западные провинции Китая с российскими дальневосточными тихоокеанскими портами. Инвестиции в эти проекты в совокупности составят 5 млрд долл., но начнут экономить китайским экспортерам по 700 млн долл. 
ежегодно с учетом сокращения пути транспортировки. Совокупный трафик по этим коридорам может достичь 45 млн т в год.

Вопросами сопряжения ЭПШП и ЕАЭС занимается Евразийская экономическая комиссия, взвешенно представляющая интересы стран ЕАЭС в области оптимизации транспортного взаимодействия с КНР. Основным требованием к выдвинутым Евразийской комиссией для обсуждения в 2017 г. с китайскими партнерами проектам стала заинтересованность как минимум двух государств ЕАЭС в реализации любого из них. Обсуждались по 12 проектов от России и Кыргызстана, десять - от Казахстана, три - от Белоруссии и два - от Армении. Половина проектов, согласованных транспортными министерствами стран ЕАЭС, предполагают развитие железнодорожного транспорта. Россия рассчитывает на повышение китайских инвестиций в строительство высокоскоростной магистрали (ВСМ) Москва - Казань, проектирование которой велось с участием китайских компаний. Потенциально эта ВСМ может быть продлена до Берлина на Западе и Пекина на Востоке, а также использована для скоростных грузоперевозок, поскольку Россия и Китай намерены создать совместное производство скоростных грузовых поездов. Рассчитывает Россия и на участие Китая в модернизации БАМа и Транссиба. Армения выдвинула проект железнодорожной ветки Армения Иран, Кыргызстан - железной дороги Китай - Кыргызстан - Узбекистан.

Проблемная для России тема - автодорожное сообщение - тоже предложена Евразийской комиссией китайским партнерам в контексте ЭПШП: в планах госкорпорации «Росавтодор» создание сети скоростных федеральных автотрасс и содействие строительству новых автодорог МТК Западная Европа - Западный Китай. Учтены и потребности стран ЕАЭС в создании логистической инфраструктуры нового уровня: несколько проектов относятся к созданию логистических центров и хабов вдоль коридоров ЭПШП, проходящих по территории стран ЕАЭС, а также вдоль российского Севморпути.

Подводя итоги, следует отметить, что Китай, Индия и другие азиатские страны нуждаются в транспортных коридорах через Евразию, чтобы осваивать платежеспособный европейский рынок. Россия, сама являющаяся «природным коридором», представляется естественным монополистом благодаря наличию надежной и развитой железнодорожной инфраструктуры. Но естественные преимущества в условиях всеобщей геополитической и экономической конкуренции перестают быть незыблемыми. Новая конфигурация международных отношений и совокупность экономических и политических факторов (падение цены на нефть, решение США переориентировать долю газового рынка ЕС на себя, изменение правил игры на энергетическом рынке ЕС и т.п.) ведут к тому, что реальная эффективность упрощенных подходов (например, оперативно протянуть трубопроводы из России в Азию и получать гарантированные сверхдоходы) близка к нулю. 


\section{РОССИЯ И МИР В ХХІ ВЕКЕ}

Сфера международных транспортных коммуникаций - вторая после рынка энергоносителей область, где поспешность в оценках и медлительность в выполнении намеченных задач могут лишить Россию дивидендов от естественных преимуществ и ввергнуть в убытки. Мониторинг действий и приоритетов стран - инициаторов создания международных транспортных коридоров (МТК) неэффективен без понимания их мотивации. Испытывающей санкционное давление России нецелесообразно поддерживать сразу все инициативы стран-партнеров, порой меняющих «территориальные компоненты» проектов без учета интересов России или в прямом противоречии с ними. Перспективнее формулировать свои, российские, предложения под эгидой масштабных проектов. К экономическим обоснованиям, сформулированным представителями стран - лоббистов транспортных проектов, в России порой относятся некритически, не всегда понимая, что выдвигаемые «аргументы» не только зависят от региональной и глобальной геополитической конъюнктуры, но и порой опираются на внешнеполитические доктрины, где идеологический компонент преобладает над экономическим.

Все это обязывают Россию к разумному балансу в отношениях с Индией и Китаем, возможно принятию на себя роли страны - интегратора важных для Евразии проектов. России уместно играть роль посредника в отношениях своих набирающих геополитическую мощь партнеров. Другой должна быть стратегия России в отношении стран со схожим потенциалом выгодоприобретателей от евразийского транзита: Ираном, Турцией, Азербайджаном. Стремление России - из геополитических соображений - держать под контролем всю активность этих государств в транспортной сфере может негативно сказаться на развитии ее инфраструктурного и логистического потенциала. Он должен быть независимым от международной конъюнктуры и служить основой геополитической и экономической состоятельности России в макрорегионе Большой Евразии.

\section{Библиография}

1. Дзядко Т. «Ямал СПГ» привлек $€ 10,6$ млрд у китайских банков // РБК. 2016. 24 апреля. URL: http://www.rbc.ru/business/29/04/2016/57232d639a7947987f649167 (Дата обращения: 15.06.2017.)

2. Ефременко Д.В. Рождение Большой Евразии // Россия в глобальной политике. 2016. № 6. URL: http://globalaffairs.ru/number/Rozhdenie-Bolshoi-Evrazii-18478 (Дата обращения: 10.09.2017.)

3. Пинюгина Е.В. КНР, Россия, Германия, Казахстан: Тенденции развития партнерства // Россия и современный мир. 2016. № 4 (93). С. 131-144.

4. Чеснаков Э. Союзное государство снижает логистическую зависимость от третьих стран. Интервью Сергея Сигачева // Сонар - 2050. 2017. 23 августа. URL: https://www. sonar2050.org/publications/soyuznoe-gosudarstvo-snijaet-logisticheskuyu-zavisimost-ot-tretih-stran/ (Дата обращения: 10.09.2017.) 
5. Эксперт: Перевозки углеводородов в Арктике к 2025 году достигнут 65 млн тонн // PRO-Arctic [Электронный pecypc]. URL: http://pro-arctic.ru/06/09/2017/news/27947\#read (Дата обращения: 02.10.2017.)

6. United Nations Conference on Trade and Development Statistical Database // URL: http://unctadstat.unctad.org (Дата обращения: 01.09.2017.)

\section{References}

Chesnakov Je. Sojuznoe gosudarstvo snizhaet logisticheskuju zavisimost' ot tret'ih stran. Interv'ju Sergeja Sigacheva // Sonar - 2050. 2017. 23 Aug. URL: https://www.sonar2050. org/publications/soyuznoe-gosudarstvo-snijaet-logisticheskuyu-zavisimost-ot-tretih-stran/ (Data obrashhenija: 10.09.2017.)

Dzjadko T. «Jamal SPG» privlek $€ 10,6$ mlrd u kitajskih bankov // RBK. 2016. 24 Apr. URL: http://www.rbc.ru/business/29/04/2016/57232d639a7947987f649167 (Data obrashhenija: 15.06.2017.)

Efremenko D.V. Rozhdenie Bol'shoj Evrazii // Rossija v global'noj politike. 2016. N 6. URL: http://globalaffairs.ru/number/Rozhdenie-Bolshoi-Evrazii-18478 (Data obrashhenija: 10.09.2017.)

Jekspert: Perevozki uglevodorodov v Arktike k 2025 godu dostignut $65 \mathrm{mln}$ tonn // PRO-Arctic [Jelektronnyj resurs]. URL: http://pro-arctic.ru/06/09/2017/news/27947\#read (Data obrashhenija: 02.10.2017.)

Pinjugina E.V. KNR, Rossija, Germanija, Kazahstan: Tendencii razvitija partnerstva // Rossija i sovremennyj mir. 2016. N 4 (93). P. 131-144.

United Nations Conference on Trade and Development Statistical Database // URL: http://unctadstat.unctad.org (Data obrashhenija: 01.09.2017.) 